\title{
Research regarding the upgrading of the attachments for balance ropes of mine hoists
}

\author{
Iosif Dumitrescu ${ }^{1}$, Danut Grecea $^{2}$, Cosmin Vitan $^{1 *}$, and Dorel Vitan ${ }^{1}$ \\ ${ }^{1}$ University of Petrosani, 20 University street, 332006, Petrosani, Romania \\ ${ }^{2}$ National Institute for Research and Development in Mine Safety and Protection to Explosion - \\ INSEMEX, 32-34 G-ral Vasile Milea Street, Petrosani, Romania
}

\begin{abstract}
The research approaches the possibilities of modernizing the cable fastening devices for balancing mining hoisting engines with a view to increase functioning safety and to decrease the costs of manufacturing. Modern means of investigation are employed so that the proposed solutions are well-grounded and display a certain degree of generality in order that the technology might also be applied to other technical circumstances in the industry of resource extraction and capitalization.
\end{abstract}

\section{Introduction}

The research is aimed at finding modular constructive solutions that allow adaptation for any mining extractive equipments. Considering that each mining operation in the Jiu Valley has another type of extraction facility due to the opening of mining in different years. The problem is of great complexity as these equipments provide safety for the mining installations due to the balancing of the lifting cables of the extraction vessels. For the sake of clarity we can mention that if such a device fails, losing the balancing cable, there are large imbalances that can cause the destruction of the technical system and serious accidents with consequences regarding the service life of the servicemen and stopping extraction of the underground production. In this picture were developed theoretical and applicative researches based on calculations, modeling, designing and subsequent experimentation under real exploitation conditions. The whole process was completed by accepting the solutions proposed by $\mathrm{CEH}(\mathrm{CNH})$ Petrosani. Wide cable fastening devices for balancing connect the hoisting vessel and the wide cable with a view to equalize vertically transported masses [2,7].

The hoisting engines in the mining industry are industrial systems displaying increased complexity and importance for the technological process of extracting useful mineral substances. Owing to the fact that this category of engines represents a decisive factor in the functioning of the mining units and to the fact that the modernization processes designed for maintaining exploitation and for increasing technical and economic performance represent the sole feasible option for continuing the processes of extraction, it is necessary to also consider, at present, the high costs of these engines as well as the declining tendency of the mining field in our country.[3, 5-6].

\footnotetext{
*Cosmin Vitan: vitan.daniel.cosmin@gmail.com
} 
The friction force and the uneven tensions within the cables of the engine have determined the need to equalize them. In order to equalize the static forces within cables, due to the uneven elongation of the cables, a technical system including a flat cable fastened through a series of devices to the vessels of the hoisting engine is employed, [1, 4]. Figure 1 displays the component elements of a hoisting plant that include the hoisting engine, the cables of the engine, the cutting wheels, the hoisting vessels, the fastening devices and the balance cables. Due to the fact that the fastening devices to the vessels of the hoisting plant wear out in time, losing their functional characteristics, their replacement is required. With these in view, this paper aims to display the researches focused on modernizing these devices, namely: designing new solutions with a view to apply them for this type of hoisting engines that is still used in industrial exploitation. A and B details show the location of the cable fastening device for balancing hoisting vessels.

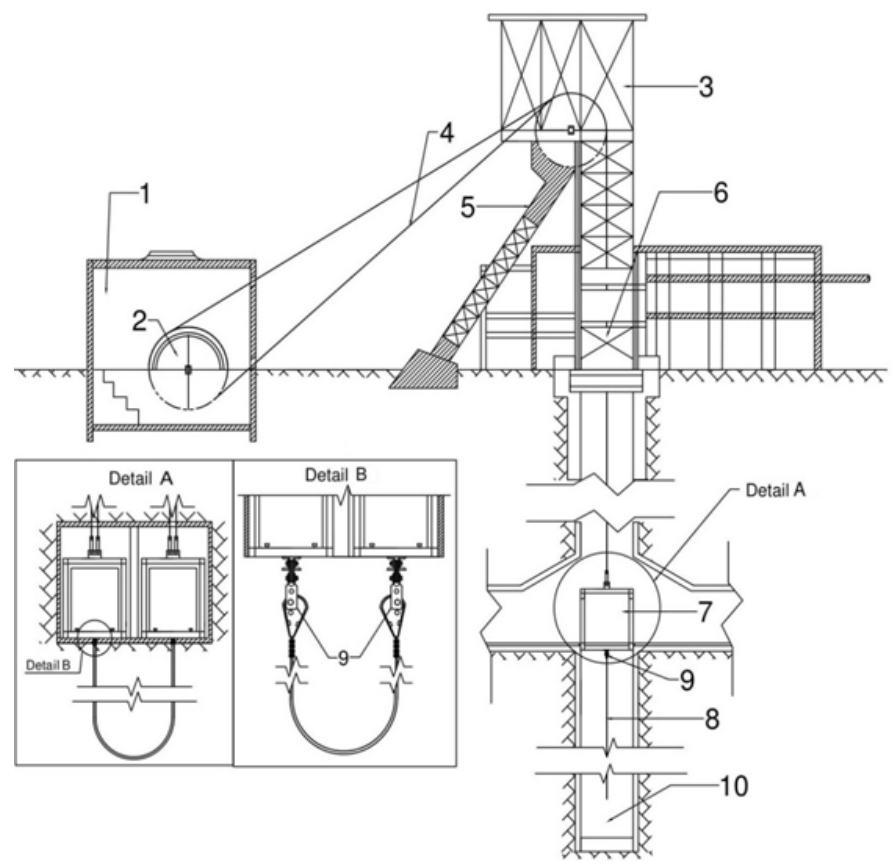

Fig. 1. Hoisting plant: 1. Shelter of hoisting engine; 2. Hoisting engine; 3. Tower with cutting wheels; 4. Cables of hoisting engine; 5. Buttress of extraction tower; 6. Ramp of surface pit; 7. Hoisting vessels; 8. Balance cable; 9. Devices for fastening balance cables; 10. Pit sump

The constructive and functional features of wide cable fastening devices for balancing are shown in Table 1. 
Table 1. Constructive and functional features of wide cable fastening devices for balancing.

\begin{tabular}{|c|c|c|c|c|c|c|}
\hline \multirow[b]{2}{*}{ No. } & \multirow{2}{*}{\multicolumn{2}{|c|}{ Appellation of feature }} & \multirow[b]{2}{*}{ UM } & \multicolumn{3}{|c|}{ Value of feature } \\
\hline & & & & $\begin{array}{l}\text { DLCLE- } \\
118 \\
\end{array}$ & $\begin{array}{l}\text { DLCLE- } \\
129\end{array}$ & $\begin{array}{c}\text { DLCLE- } \\
135\end{array}$ \\
\hline 1. & \multicolumn{2}{|c|}{ Maximal static load } & tons $/ \mathrm{kN}$ & $2 / 20$ & $3.5 / 35$ & $5.5 / 55$ \\
\hline 2. & \multicolumn{2}{|c|}{ Section of wide cable } & $\mathrm{mm}$ & $\begin{array}{c}106 \times 15.5 \\
118 \times 17\end{array}$ & $\begin{array}{l}124 \times 18 \\
129 \times 19\end{array}$ & $135 \times 20$ \\
\hline 3. & \multirow{2}{*}{\multicolumn{2}{|c|}{$\begin{array}{l}\text { Cable's specific mass } \\
\text { Module for fastening the } \\
\text { cable }\end{array}$}} & $\mathrm{kg} / \mathrm{m}$ & $5.447 / 6.726$ & $7.558 / 8.128$ & 8.865 \\
\hline 4. & & & - & \multicolumn{3}{|c|}{ with loop and eccentric heart } \\
\hline 5. & \multicolumn{2}{|c|}{ Diameter of bolts } & $\mathrm{mm}$ & 60 & 70 & 70 \\
\hline 6. & \multicolumn{2}{|c|}{$\begin{array}{l}\text { Thickness of the junction } \\
\text { plate to the skip }\end{array}$} & $\mathrm{mm}$ & 40 & 48 & 40 \\
\hline 7. & \multicolumn{2}{|c|}{$\begin{array}{l}\text { Number of clamps for } \\
\text { fastening the wide cable }\end{array}$} & piece & 6 & 6 & 6 \\
\hline 8. & \multicolumn{2}{|c|}{ Distance between clamps } & $\mathrm{mm}$ & 120 & 120 & 120 \\
\hline \multirow{3}{*}{9.} & \multirow{3}{*}{$\begin{array}{l}\text { Gauge } \\
\text { sizes }\end{array}$} & $\begin{array}{l}\text { Length } \\
\text { (height) }\end{array}$ & $\mathrm{mm}$ & 1327 & 1577 & 1706 \\
\hline & & Width & $\mathrm{mm}$ & 380 & 460 & 500 \\
\hline & & Thickness & $\mathrm{mm}$ & 238 & 250 & 258 \\
\hline 10. & \multicolumn{2}{|c|}{ Mass } & $\mathrm{kg}$ & 190 & 248 & 290 \\
\hline
\end{tabular}

\section{Construction and functioning of devices}

The main constructive and functional parts of the wide cable fastening devices for balancing, namely DLCLE-118, DLCLE-129 and DLCLE-135, are displayed in Figures 2 a. and 2 b.

The three types of sizes of the wide cable fastening devices for balancing have the same constructive form; nonetheless, the difference consists in the sizes of the component elements, which have to bear different loads, depending on the features of the balancing wide cable.

In accordance with Figure 2a, such a device includes a series of strength elements which connect the bottom of the hoisting vessel and the eccentric heart, whose functional width is determined by the width of the wide cable, as well as a series of clamps for fastening the end of the cable wrapped round the heart. 


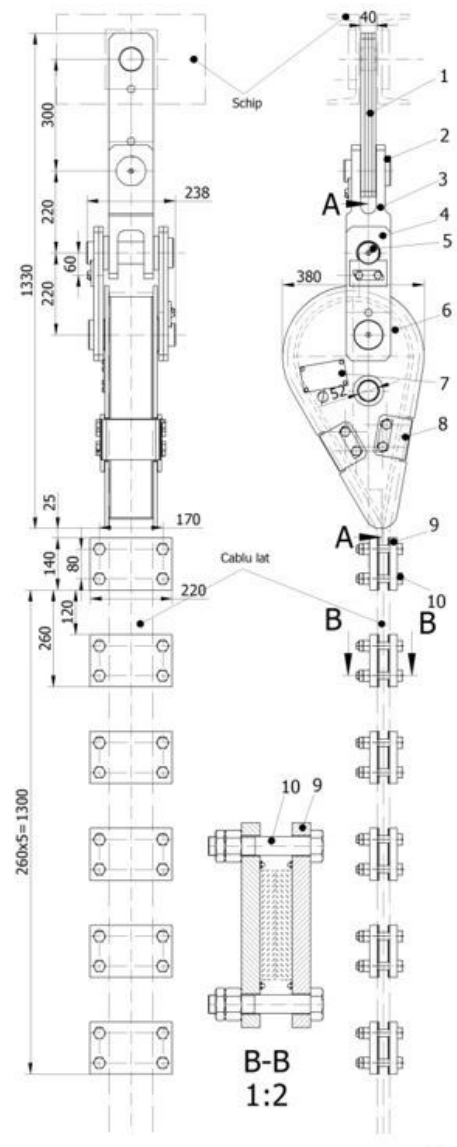

a.

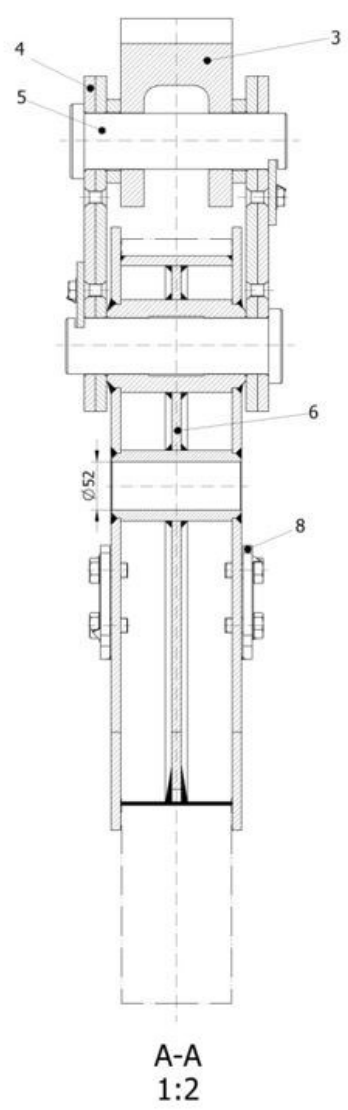

A-A

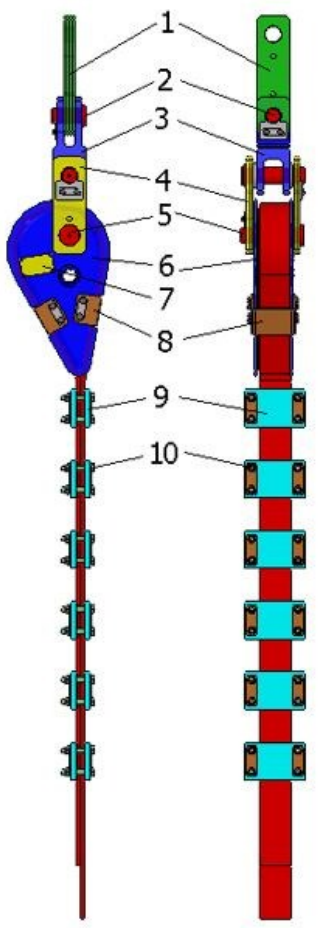

b.

Fig. 2. Wide cable fastening deice for balancing, DLCLE 118, 129, 135

The whole device is attached to the hoisting vessel by way of junction plate 1 , which is a strength structure made of four clinched steel boards and processed through splinting to acquire nominal sizes. The connection to the eccentric heart 6 is provided by a fork 3 and two junction plates 4 , consisting in two clinched steel boards; the connection among the three elements is provided by bolts 2 and 5, made of heat treated alloyed steel.

The eccentric heart is a welded metal construction, Figure 3, including a central plate that shapes and locates the two bushings, while the wrapping plate and the outer plates shape the ditch along which the end of the wide cable wraps for equalizing. The heart also includes, besides the bushing of bolt 5 , a hole used for supporting the device with a view to mounting the cable. Label 7 is attached to the heart in order to be able to identify the device; two fasteners 8 are also attached for fastening the wide cable within the ditch of the metallic heart. 

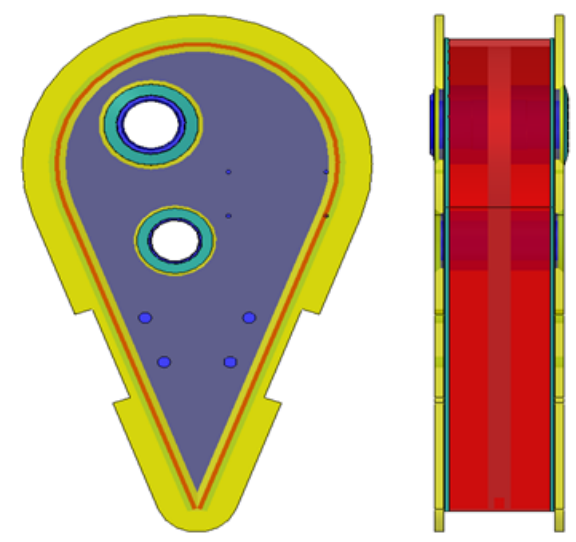

Fig. 3. Eccentric heart DLCLE 118

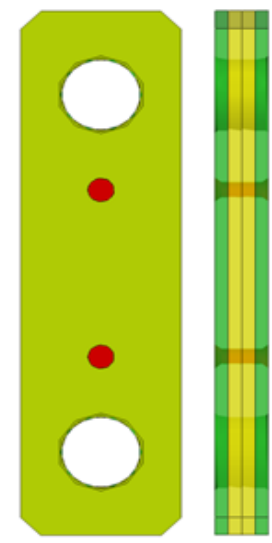

Fig. 4. Skip's junction plate

The free end of the cable is wrapped along about $1,500 \mathrm{~mm}$ over the cable that enters the heart, the two branches being attached by six double clamps 9 , each of them displaying four tightening screws 10, with bolt nuts and jam nuts.

When manufacturing the skip's junction plate, Figure 4, the intermediary junction plate and the inferior and superior plates of the eccentric heart the following conditions should be observed:

- It is forbidden the hot straightening of the sheet-metals the previously mentioned subassemblies are made of;

- The cutting of the piece from the sheet-metal is made along the outline through splinting or thermal cutting, when a processing addition of, at least, $10 \mathrm{~mm}$, should be included; this addition will be removed through splitting;

- The cutting of the piece should be done so that the direction of plate lamination matches the direction of plate stressing, along the piece.

In the case of manufacturing subassemblies made of plates, the exterior and the interior plates are bind in packages and the rivet bores are produced; further, they are fixed through riveting, while the other bores are being processed. After assembling the package of plates through riveting, the end of the rivet is processed so that it does not exceed the external plate.[8].

With a view to manufacture the connecting bolts and forks, it is forbidden to forge the material; only the mechanical processing of the material is allowed. 
Before mounting the device at the place of use, all the component parts of the device are checked. The component elements that display failures or damages that might influence negatively the functioning of the device are not admitted.

The hoisting vessel at which the balancing device is fastened sits on safety catches or on a safety platform.

To the top, the device is attached through bolts to the hoisting vessel, while in its lower part a wide cable is mounted through wrapping it on the eccentric heart and fastening by way of clamps.[9].

\section{Size checking of the devices}

Starting from the mathematic balance model of the cable and the metallic heart, displayed in Figure 5, and from the non-gliding condition of the end of the cable blocked between the clamps and the cable, the relation determining the tightening force of the clamps comes out:

$$
N_{1}=\frac{G \cdot e^{-\mu \cdot \theta}}{\mu_{1} \cdot\left(1+e^{-\mu \cdot \theta}\right)}, \mathrm{N}
$$

where: $G$ is the maximal weight of the balancing cable, $G=20000 \mathrm{~N} ; \mu$ - coefficient of friction between the cable and the metallic heart, $\mu=0.1 ; \theta$ - wrapping angle of the cable on the metallic heart, $\theta=220^{\circ} ; \mu_{l}$ - friction coefficient between cables, $\mu_{l}=0.1$.

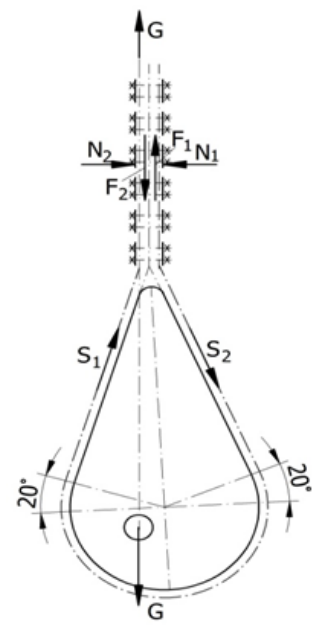

Fig. 5. Mathematic model of cable's fastening forces

In the case of a dynamic coefficient of the hoisting plant of $1.6 \ldots 2$ and a safety coefficient higher than 10, a number of twenty-one M20 screws manufactured from OLC35 with a ductility limit of $370 \mathrm{Mpa}$ results.[10],[11]

Junction plates and the fork were checked for bending flexure and shearing stress in the area of the bolts as well as for contact pressure between the surfaces of their bores and the bolts.

The bolts were checked for mixed bending flexure and shearing stress; in the case of a safety coefficient higher than 10, one of the improved alloyed steels - 42MoCr11, 31MoCr11, $31 \mathrm{MnCrSi} 11$ or $25 \mathrm{MnCrSi} 11$ - should be used.[12]. 


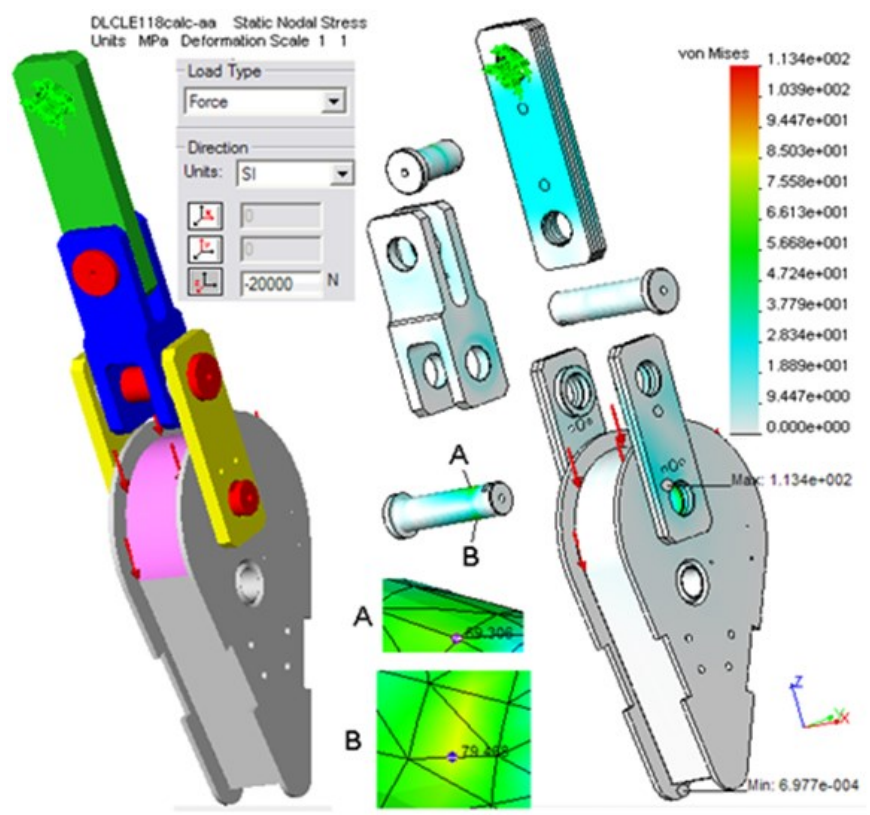

Fig. 5. Mathematic model of cable's fastening forces

\section{Conclusion}

This paper shows a synthesis of the results of the researches undergone in collaboration with Complexul Energetic Hunedoara (Hunedoara Power Complex) and meant to modernize and widely use the cable fastening devices for balancing in the case of the existing hoisting engines.

When elaborating the documentation, a series of imposed restrictions were considered and a series of new solutions came out, as follows:

- Technologically simplified constructive solutions (manufacturing eccentric heart and clamps through welding as compared with their manufacturing through casting);

- Increased standardizing of the constructive solutions for the wide cable fastening devices that are part of the multi-cable hoisting plants in the Jiu Valley. This was quite a difficult task as it was necessary to preserve the interchange between these standardized solutions and the existing constructions;

- Use of constructive solutions that were verified in practice on similar devices;

- Preservation of the existing safety coefficient and its increase in some cases;

- Decrease of the cost price through diminishing manufacturing costs.

This paper is a technical and applicative work and the results obtained while exploiting its features under industrial circumstances show the credibility of the solutions adopted. 


\section{References}

1. C. D. Adam, (Universitas Publishing House), Petroșani (2008)

2. D. Badita (Popescu), G. Tutuianu, D. Grecea, A. Sultan, Balkan Mining Congress (2015)

3. D. Radu, (Universitas Publishing House), Petrosani (2017)

4. F. D. Popescu, G. Dimirache, (Editura Focus), Petrosani (2011)

5. F. D. Popescu, I. Mitran, Proceedings of the 8th WSEAS International Conference on SYSTEM SCIENCE and SIMULATION in ENGINEERING - ICOSSSE '09, (2009)

6. F. D. Popescu, I. Mitran, WSEAS TRANSACTIONS on SYSTEMS and CONTROL, 4, $509-$ $518(2009)$

7. F. D. Popescu, (Focus Publishing House), Petrosani (2010)

8. F. D. Popescu, Proceedings of the 12th International Conference on Artificial Intelligence, Knowledge Engineering and Data Bases - AIKED '13 (2013)

9. F. D. Popescu, S. M. Radu, (LAP LAMBERT Academic Publishing), Saarbrucken Germany (2014)

10. F. Popescu, A. Andraş, I. Kertesz, 17th International Multidisciplinary Scientific GeoConference SGEM 2017, 17, 901-908 (2017)

11. G. Muscă, (Junimea Publishing House), Iasi (2006)

12. PT-C 09 - Technical prescriptions concerning the exploitation, maintenance and control of hoisting plants, cables and cable fastening devices. 